\title{
Descarte e congelabilidade do sêmen de touros de raças zebuínas e taurinas em central de inseminação artificial no Brasil
}

[Semen discarded and freezing ability of Zebu and European bulls from a Brazilian artificial insemination centre]

\author{
M.C. Anchieta ${ }^{1}$, V.R. Vale Filho ${ }^{2 *}$, E. Colosimo ${ }^{3}$, I.B.M. Sampaio ${ }^{2}$, V.J. Andrade ${ }^{2}$ \\ ${ }^{1}$ Aluna de Mestrado - EVUFMG \\ ${ }^{2}$ Escola de Veterinária da UFMG \\ Caixa postal 567 \\ 30123-970 - Belo Horizonte, MG \\ ${ }^{3}$ Instituto de Ciências Exatas da UFMG
}

\begin{abstract}
RESUMO
Foram analisadas as características do sêmen obtido de 250 touros de raças zebuínas e 144 touros de raças taurinas em uma central de inseminação artificial, no Sudeste brasileiro. Consideraram-se dois períodos de colheita: chuvoso e seco, ambos com temperaturas elevadas $\left(>19,0^{\circ} \mathrm{C}\right)$. Também foram estudadas as causas dos descartes e a congelabilidade do sêmen. $\mathrm{O}$ sêmen das raças taurinas foi superior ao das raças zebuínas nos aspectos turbilhonamento, motilidade e concentração espermática e inferior quanto ao volume $(\mathrm{P}<0,05)$. $\mathrm{O}$ descarte foi maior na estação chuvosa $(\mathrm{P}<0,05)$. $\mathrm{O}$ sêmen descartado por características físicas foi maior nas raças zebuínas e por características morfológicas nas raças taurinas $(\mathrm{P}<0,05)$. A congelabilidade do sêmen das raças taurinas foi superior à dos touros das raças zebuínas $(\mathrm{P}<0,05)$.
\end{abstract}

Palavras-chave: bovino, sêmen, andrologia, variação sazonal

\begin{abstract}
Semen characteristics from 250 Zebu and 144 European bulls were described and compared among season and species. All bulls were selected as donors and during five years were always stationed at an Artificial Insemination Center in Southeast of Brazil, where temperatures were above $19^{\circ} \mathrm{C}$ in both dry and rainy seasons. Contingency tables and Tukey's test were used to check associations and to compare group means, respectively. Semen from European breeds showed higher swirl, motility and concentration values than those of Zebu breeds $(P<0.05)$. Semen volume was higher for Zebu breeds $(P<0.05)$. There were more discarded ejaculates in the rainy season $(P<0.05)$. A major cause for discarding ejaculates was undesirable physical characteristics for the Zebu and morphological characteristics for the European breeds $(P<0.05)$. Semen freezing ability values for the European breeds were higher.
\end{abstract}

Keywords: cattle, semen, andrology, seasonal variation

\section{INTRODUÇÃO}

No Brasil, tem havido esforços para que os touros apresentem alta performance reprodutiva e alta eficiência de fecundação, resultantes da inseminação artificial com sêmen de elevada motilidade, alto vigor e baixo índice de espermatozóides anormais ejaculados e congelados (Vale Filho, 1989; 1997).

Condições climáticas que afetam a gametogênese podem levar à baixa eficiência reprodutiva de touros (Vale Filho, 1986; 2001).

Recebido para publicação em 27 de março de 2004

Recebido para publicação, após modificações, em 23 de dezembro de 2004

* Autor para correspondência (corresponding author)

E-mail: clinica@vet.ufmg.br 
Kodagali (1963) e Tomar e Kanaujia (1970), na Índia, verificaram que o volume do ejaculado de touros de raças zebuínas foi maior nas estações mais frias. No Brasil (Pinto, 1987) e no México (Hernandez et al., 1991) o volume do ejaculado foi maior nos períodos mais quentes. Quanto à pluviosidade, foi observado maior volume na estação seca na Etiópia (Tegegne et al., 1994). Nos touros de raças taurinas, o volume do ejaculado não se alterou segundo a estação no Canadá (Mathevon et al., 1998), mas foi maior em épocas frias na Índia (Sudararaman et al., 2000). A comparação entre touros de raças zebuínas e taurinas, criados nas mesmas condições de ambiente, revelou que o volume dos ejaculados foi similar entre as estações nos EUA (Fields et al., 1979) e na Nigéria (KumiDiaka et al., 1981), maior no inverno nas duas subespécies em Cuba (Menendez-Buxadera et al., 1983), ou maior nos períodos chuvosos, também em ambas subespécies, no Brasil (Silva, 1981) e Nigéria (Rekwot et al., 1987).

A motilidade espermática em touros de raças zebuínas foi maior em períodos de temperaturas mais baixas na Índia (Kodagali, 1962), no verão no México (Hernandez et al., 1991), ou na estação seca na Etiópia (Tegegne et al., 1994). Nos touros de raças taurinas, Mathevon et al. (1998), no Canadá, não verificaram diferenças entre as estações e Sudararaman et al. (2000), na Índia, observaram menor motilidade espermática nas estações caracterizadas pela presença de ventos. No mesmo ambiente de região considerada semi-tropical dos EUA, as duas subespécies apresentaram maior motilidade espermática no período outono-inverno (Fields et al., 1979) ou foram similares entre as estações da Nigéria (Rekwot et al., 1987).

O vigor apresentado pelos espermatozóides de touros de raças zebuínas variou entre as estações, sendo maior no inverno, na Índia (Tomar e Kanaujia, 1970), ou na estação seca, no Brasil (Pinto, 1987) e na Etiópia (Tegegne et al., 1994).

A concentração espermática $/ \mathrm{ml}$ do ejaculado de touros de raças zebuínas foi maior em períodos de temperaturas mais frias na Índia (Kodagali, 1962; 1963; Tomar e Kanaujia, 1970) ou no verão, no México (Hernandez et al., 1991). Em relação à pluviosidade, a concentração foi maior nos períodos de seca na Etiópia (Tegegne et al., 1994). Para os ejaculados de touros de raças taurinas, também foi verificada maior concentração espermática nas estações mais frias na Índia (Sudararaman et al., 2000), na Suécia (Söderquist et al., 1996) e no Canadá (Mathevon et al., 1998). Entre touros de raças zebuínas e taurinas, sob as mesmas condições climáticas, a concentração de espermatozóides nos ejaculados dos touros de raças taurinas foi maior do que a de raças zebuínas nos EUA (Fields et al., 1979), e também maiores nos períodos chuvosos na Nigéria (Kumi-Diaka et al., 1981; Rekwot et al., 1987).

O percentual de espermatozóides anormais no sêmen, na Nigéria, foi menor nos touros de raças taurinas do que nos de raças zebuínas, em períodos chuvosos (Kumi-Diaka et al., 1981) mas, segundo Rekwot et al. (1987), ainda na Nigéria, foi semelhante entre as duas subespécies, embora menor na estação chuvosa do que na estação seca. No Brasil, Koivisto et al. (1998) verificaram menor número de espermatozóides anormais no inverno nos touros de raças zebuínas.

No Brasil, a qualidade do sêmen de touros de raças zebuínas foi considerada inferior, especialmente no período de seca, por Silva (1981), enquanto Koivisto et al. (1998) associaram a qualidade do sêmen (percentagem de espermatozóides anormais) das duas subespécies com altas temperatura e umidade relativa do ar, presentes nas estações de primavera e verão. Em Cuba, ambas as subespécies apresentaram sêmen de melhor qualidade (motilidade, concentração, percentagem de espermatozóides vivos) no período frio (Menendez-Buxadera et al., 1983). $\mathrm{Na}$ Índia, as raças zebuínas apresentaram sêmen de melhor qualidade (volume, $\mathrm{pH}$, concentração, movimento de massa, motilidade) na estação quente-chuvosa e as raças taurinas na estação quente-seca (Djimde e Weniger, 1984). Na Nigéria, a estação chuvosa propiciou melhor qualidade de sêmen (volume, concentração, percentual de espermatozóides normais, percentagem de espermatozóide vivos) para ambas as subespécies (Rekowt et al., 1987).

O presente trabalho objetivou registrar a influência climática sobre a produção e a congelabilidade do sêmen, bem como ressaltar a importância de rigor nos critérios seletivos para touros de raças zebuínas ou taurinas instalados 
em uma central de inseminação artificial no Sudeste brasileiro.

\section{MATERIAL E MÉTODOS}

Para o estabelecimento da qualidade dos ejaculados obtidos, das causas dos descartes efetuados e da quantidade de sêmen produzido para uso comercial, foram estudados 394 touros, 250 de cinco raças zebuínas, com predominância das raças Nelore (64\%) e Gir (23\%), e 144 de 18 raças taurinas, com predominância da raça Holandesa $(53,5 \%)$. Eles foram selecionados para doarem sêmen durante cinco anos em uma central de inseminação artificial, localizada na latitude $21^{\circ} 08^{\prime} \mathrm{S}$, longitude $47^{\circ} 59^{\prime} \mathrm{W}$, com altitude média de 549,5m. Forneceram 21.133 ejaculações, 13.785 de raças zebuínas e 7.348 de raças taurinas.

A seleção inicial dos touros baseou-se em: (1) histórico/anamnese e número de filhos já nascidos, em relação ao tempo de uso; (2) avaliação clínica geral (higidez e bons aprumos); (3) normalidade do sistema genital (aferição da circunferência escrotal e mensurações de comprimento e largura testiculares); (4) comportamento sexual normal relativo à libido e à habilidade sexual; (5) espermiograma (Vale Filho, 1997, 2001). Do total de 21.133 ejaculados, 1.265 foram usados em análises iniciais, para determinação da normalidade do sêmen e da curva de produção gamética de cada touro.

Os touros selecionados foram mantidos em piquetes de $400 \mathrm{~m}^{2}$, divididos por cerca elétrica dupla, com abrigos altos de "Epox", sem paredes e com ampla ventilação, servindo cada um, a quatro unidades. Os piquetes eram dispostos na forma de leque, e providos de grama estrela africana (Cynodon nlefluensis) disponível para pastoreio, além de cochos com sal mineral, ração balanceada e água. A quantidade de ração para cada touro dependia de sua capacidade de consumo e da qualidade do sêmen (volume, turbilhonamento, motilidade, vigor, concentração, percentual de espermatozóides anormais), controlada continuamente pelo espermiograma.

Os dados meteorológicos da localidade foram registrados pela vizinha Estação Experimental de Ribeirão Preto, pertencente ao Instituto Agronômico de Campinas (SP). No período do estudo (1974-1979), a temperatura média mensal variou de 19,2 a $24,7^{\circ} \mathrm{C}$ e a precipitação pluviométrica mensal de 23,7 a 307,2mm (Fig. 1); a umidade relativa do ar variou de 56,1 a 80,1\% (Fig. 2).

Os ejaculados foram obtidos pelo método da vagina artificial, contudo, alguns animais zebuínos demandaram o método de colheita por eletroejaculação até seu condicionamento àquela condição. Os 21.133 ejaculados foram submetidos aos critérios de seleção preconizados por Vale Filho $(1989,1997)$ e Fonseca et al. (1992). Com base neles, foram distribuídos em sete categorias, sendo seis para ejaculados descartados e uma para ejaculados congelados: (1) ejaculados dentro dos padrões mínimos de congelação, mas provenientes de touros ainda em processo de seleção para serem definidos como doadores de sêmen; (2) ejaculados impróprios para congelamento por se apresentarem com baixa motilidade $(<60 \%)$ e/ou índice $<4$ para vigor (0-5); (3) ejaculados impróprios para congelamento por apresentarem número de espermatozóides anormais acima de padrões preestabelecidos; (4) ejaculados impróprios para congelação por apresentarem, simultaneamente, as características descritas nos dois itens anteriores; (5) ejaculados aptos para congelação, mas provenientes de touros com estoque de sêmen suficiente para comercialização; (6) ejaculados inicialmente aptos para congelação, mas descartados por recuperação física insuficiente pós-congelação, em relação ao padrão mínimo estabelecido tecnicamente (motilidade $\geq 35 \%$ e vigor $>4$ ); (7) ejaculados efetivamente congelados e destinados à comercialização.

$\mathrm{Na}$ análise estatística, as respostas quantitativas (volume, turbilhonamento, motilidade, vigor e concentração) do fatorial $2 \times 2$ (duas subespécies e duas estações climáticas), com números diferentes de repetições, seguiram delineamento inteiramente ao acaso. Foram processados pelo software Statistical package for social science (Statistical..., 1997) $(\mathrm{P}<0,05)$, e tiveram suas médias comparadas pelo teste Tukey (Snedecor e Cochran, 1989). 


\section{CLIM O G R A M A D A R E G I Ã O DE RIBEIR Ã O PRETO} ( S P )

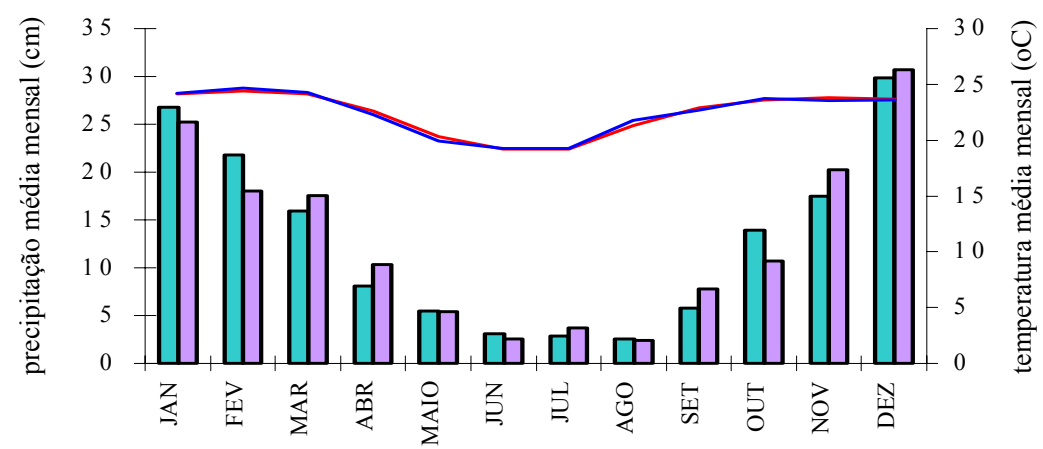

एpluv.61/90 שpluv.74/79 temp.61/90 temp.74/79

Figura 1. Climograma histórico (1961-1990¹) e no período de estudo (1974-1979²) da região de Ribeirão Preto (SP).

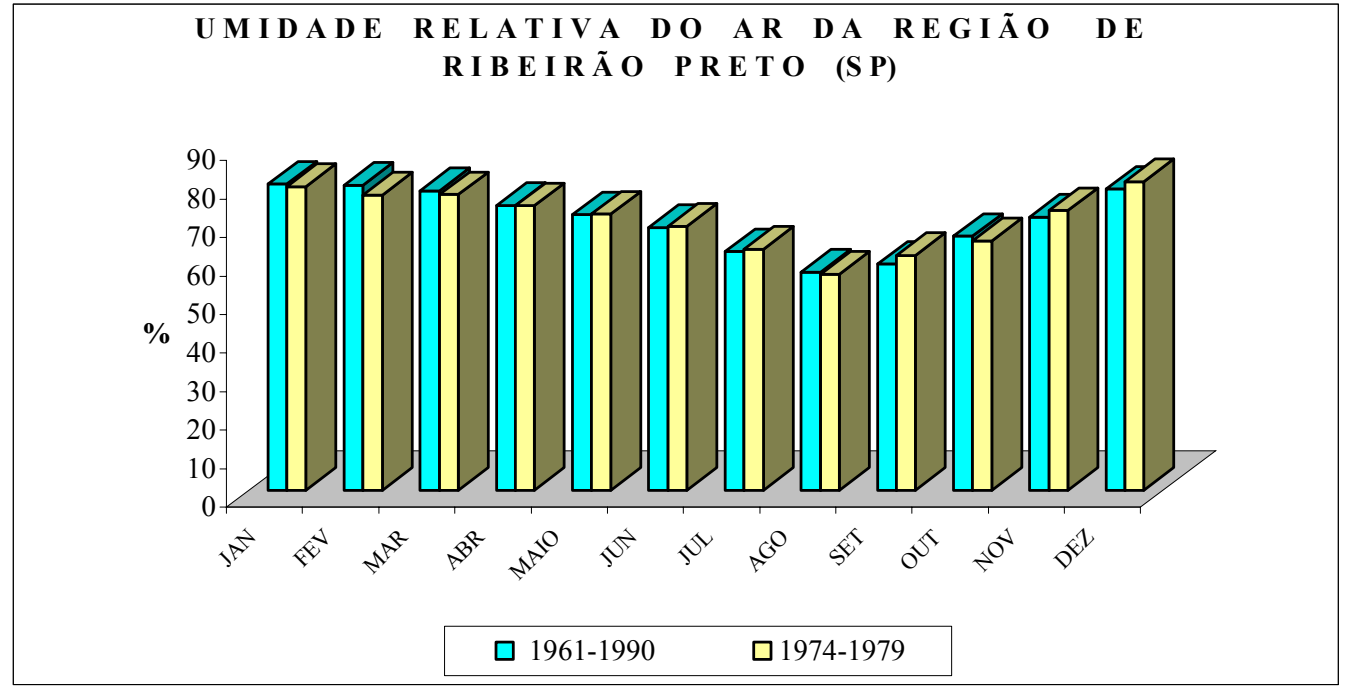

Figura 2. Umidade relativa do ar histórica (1961-1990³) e no período de estudo (1974-1979²) da região de Ribeirão Preto (SP)

\footnotetext{
${ }^{1}$ ABREU, D.R. (denise@ccc.iac.br) Dados mensais de temperatura média máxima e mínima, (max + min)/2 1943 a 2000 e total de chuva - 1937 a 2000; Estação Experimental de Ribeirão Preto - SP. Campinas: IAC, 2001.

2 ABREU, D.R. (denise@ccc.iac.br) Temperatura média diária, totais pluviométricos, umidade relativa - 1974-1979; Estação Experimental de Ribeirão Preto - SP. Campinas: IAC, 2001.

3 ABREU, D.R. (denise@ccc.iac.br) Normais climatológicas - 1961-1990; Estação Experimental de Ribeirão Preto - SP. Campinas: IAC, 2001.
} 
A dispersão de freqüência dos ejaculados (selecionados ou não) segundo as subespécies, dentro de cada estação climática foi medida em tabelas de contingência $(2 \times 2)$, com posterior aplicação do teste qui-quadrado para detectar eventuais associações ( seleção de sêmen com subespécie, dentro de cada estação). A mesma estratégia permitiu comparar o efeito de estação para cada subespécie.

\section{RESULTADOS E DISCUSSÃO}

Tendo em vista a constância de temperaturas elevadas e a delimitação das precipitações pluviométricas na região da central de inseminação artificial, além da umidade relativa do ar, foram consideradas apenas duas estações climáticas anuais: quente-chuvosa e quente-seca. Dessa maneira, a distribuição dos ejaculados segundo as categorias estabelecidas é apresentada na Tab. 1.

As características físicas dos ejaculados de acordo com a subespécie e a estação de colheita antes da congelação são apresentadas nas Tab. 2 e 3

O volume do ejaculado nas duas subespécies foi maior $(\mathrm{P}<0,05)$ na estação seca, época de temperaturas também mais baixas. Nos touros de raças zebuínas o volume foi maior $(\mathrm{P}<0,05)$ do que nos de raças taurinas, resultado semelhante aos de Rekwot et al. (1978), Menendez Buxadera et al. (1983), Tegegne et al. (1994) e Sudararaman et al. (2000). Silva (1981), verificou maior volume na época de chuvas.

Tabela 1. Distribuição dos ejaculados de touros zebuínos e taurinos segundo a categoria e a estação climática, antes da congelação

\begin{tabular}{|c|c|c|c|c|c|c|c|c|c|c|c|c|c|c|}
\hline \multirow{3}{*}{$\begin{array}{l}\text { Sub- } \\
\text { espécie }\end{array}$} & \multicolumn{12}{|c|}{ Descartado } & \multirow{2}{*}{\multicolumn{2}{|c|}{$\frac{\text { Congelado }}{7}$}} \\
\hline & \multicolumn{2}{|c|}{1} & \multicolumn{2}{|c|}{2} & \multicolumn{2}{|c|}{3} & \multicolumn{2}{|c|}{4} & \multicolumn{2}{|c|}{5} & \multicolumn{2}{|c|}{6} & & \\
\hline & $\mathrm{C}$ & $\mathrm{S}$ & $\mathrm{C}$ & $\mathrm{S}$ & $\mathrm{C}$ & $\mathrm{S}$ & $\mathrm{C}$ & $\mathrm{S}$ & $\mathrm{C}$ & $\mathrm{S}$ & $\mathrm{C}$ & $\mathrm{S}$ & $\mathrm{C}$ & $\mathrm{S}$ \\
\hline Zebuína & 367 & 353 & 1762 & 1557 & 262 & 269 & 449 & 423 & 132 & 180 & 1054 & 1049 & 2552 & 3376 \\
\hline$(\%)$ & $(2,7)$ & $(2,6)$ & $(12,8)$ & $(11,3)$ & $(1,9)$ & $(1,9)$ & $(3,3)$ & $(3,0)$ & $(1,0)$ & $(1,3)$ & $(7,6)$ & $(7,6)$ & $(18,5)$ & $(24,5)$ \\
\hline Taurina & 300 & 245 & 905 & 716 & 176 & 159 & 178 & 238 & 181 & 141 & 467 & 366 & 1589 & 1687 \\
\hline$(\%)$ & $(4,1)$ & $(3,3)$ & $(12,3)$ & $(9,7)$ & $(2,4)$ & $(2,2)$ & $(2,4)$ & $(3,2)$ & $(2,5)$ & $(1,9)$ & $(6,4)$ & $(5,0)$ & $(21,6)$ & $(23,0)$ \\
\hline Total & 667 & 598 & 2667 & 2273 & 438 & 428 & 627 & 661 & 313 & 321 & 1521 & 1415 & 4141 & 5063 \\
\hline
\end{tabular}

1: sêmen de touros em processo de seleção para doador; 2: com características físicas insuficientes (motilidade e vigor) do sêmen; 3 : com características morfológicas anormais dos espermatozóides; 4: somatório dos itens 2 e 3; 5: com excesso de doses em estoque; 6: com recuperação física pós-congelação, insuficiente; 7: apto para congelação.

C: estação chuvosa; S: estação seca.

Tabela 2. Volume $(\mathrm{ml})$ e concentração espermática $/ \mathrm{ml}\left(\times 10^{6}\right)$ do sêmen fresco de touros zebuínos e taurinos, nas duas estações climáticas

\begin{tabular}{|c|c|c|c|c|}
\hline \multicolumn{5}{|c|}{ Volume } \\
\hline & \multicolumn{4}{|c|}{ Estação } \\
\hline & \multicolumn{2}{|c|}{ Chuvosa } & \multicolumn{2}{|c|}{ Seca } \\
\hline Sub-espécie & $\mathrm{n}$ & Média \pm DP & $\mathrm{n}$ & Média $\pm \mathrm{DP}$ \\
\hline Zebuína & 6558 & $13,1 \pm 6,8 \mathrm{Ba}$ & 7183 & $13,5 \pm 6,9 \mathrm{Aa}$ \\
\hline Taurina & 3791 & $9,6 \pm 3,9 \mathrm{Bb}$ & 3547 & $10,0 \pm 4,2 \mathrm{Ab}$ \\
\hline \multicolumn{5}{|c|}{ Concentração espermática/ml } \\
\hline & \multicolumn{4}{|c|}{ Estação } \\
\hline & \multicolumn{2}{|c|}{ Chuvosa } & \multicolumn{2}{|c|}{ Seca } \\
\hline Sub-espécie & $\mathrm{n}$ & Média $\pm D P$ & $\mathrm{n}$ & Média $\pm D P$ \\
\hline Zebuína & 6561 & $888,8 \pm 616,7 \mathrm{Bb}$ & 7176 & $931,0 \pm 634,1 \mathrm{Ab}$ \\
\hline Taurina & 3791 & $1447,6 \pm 633,1 \mathrm{Aa}$ & 3542 & $1463,0 \pm 633,1 \mathrm{Aa}$ \\
\hline
\end{tabular}

Nas linhas, letras maiúsculas distintas indicam valores diferentes $(\mathrm{P}<0,05)$

Nas colunas, letras minúsculas distintas indicam valores diferentes $(\mathrm{P}<0,05)$.

Obs.: os valores de $\mathrm{n}$ diferem porque nem todos os dados estavam disponíveis no levantamento dos dados. 
Descarte e congelabilidade do sêmen de touros...

Tabela 3. Turbilhonamento(0-5), motilidade(\%) e vigor(0-5) do sêmen fresco de touros zebuínos e taurinos, nas duas estações climáticas

\begin{tabular}{|c|c|c|c|c|}
\hline \multicolumn{5}{|c|}{ Turbilhonamento } \\
\hline & \multicolumn{4}{|c|}{ Estação } \\
\hline & \multicolumn{2}{|c|}{ Chuvosa } & \multicolumn{2}{|c|}{ Seca } \\
\hline Sub-espécie & $\mathrm{n}$ & Média $\pm \mathrm{DP}$ & $\mathrm{n}$ & Média $\pm \mathrm{DP}$ \\
\hline Zebuína & 6563 & $3,3 \pm 1,1 \mathrm{Ab}$ & 7171 & $3,2 \pm 1,1 \mathrm{Ab}$ \\
\hline Taurina & 3789 & $3,8 \pm 1,1 \mathrm{Aa}$ & 3547 & $3,8 \pm 1,1 \mathrm{Aa}$ \\
\hline \multicolumn{5}{|c|}{ Motilidade } \\
\hline & \multicolumn{4}{|c|}{ Estação } \\
\hline & \multicolumn{2}{|c|}{ Chuvosa } & \multicolumn{2}{|c|}{ Seca } \\
\hline Sub-espécie & $\mathrm{n}$ & Média $\pm \mathrm{DP}$ & $\mathrm{n}$ & Média $\pm \mathrm{DP}$ \\
\hline Zebuína & 6559 & $59,2 \pm 12,2 \mathrm{Bb}$ & 7171 & $60,7 \pm 12,1 \mathrm{Ab}$ \\
\hline Taurina & 3783 & $60,6 \pm 11,9 \mathrm{Ba}$ & 3543 & $61,3 \pm 12,4 \mathrm{Aa}$ \\
\hline \multicolumn{5}{|c|}{ Vigor } \\
\hline & \multicolumn{4}{|c|}{ Estação } \\
\hline & \multicolumn{2}{|c|}{ Chuvosa } & \multicolumn{2}{|c|}{ Seca } \\
\hline Sub-espécie & $\mathrm{n}$ & Média $\pm D P$ & $\mathrm{n}$ & Média $\pm D P$ \\
\hline Zebuína & 6559 & $4,7 \pm 0,6 \mathrm{Ba}$ & 7171 & $4,8 \pm 0,5 \mathrm{Aa}$ \\
\hline Taurina & 3784 & $4,8 \pm 0,6 \mathrm{Aa}$ & 3543 & $4,8 \pm 0,6 \mathrm{Aa}$ \\
\hline
\end{tabular}

Nas linhas, letras maiúsculas distintas indicam valores diferentes $(\mathrm{P}<0,05)$.

Nas colunas, letras minúsculas distintas indicam valores diferentes $(\mathrm{P}<0,05)$.

Obs.: os valores de $\mathrm{n}$ diferem porque nem todos os dados estavam disponíveis no levantamento dos dados.

A estação não teve efeito sobre a concentração espermática $/ \mathrm{ml}$ nos touros de raças taurinas $(\mathrm{P}>0,05)$, enquanto que nos zebuínos ela foi menor $(\mathrm{P}<0,05)$ na estação chuvosa, ao contrário das observações de Rekwot et al. (1987), mas semelhante às de Tegegne et al. (1994). Nas raças taurinas a concentração espermática foi maior do que nas zebuínas $(\mathrm{P}<0,05)$ nas duas estações climáticas, resultado já mencionado por Fields et al. (1979) e Kumi-Diaka et al. (1981).

Houve diferença $(\mathrm{P}<0,05)$ no turbilhonamento entre as subespécies nas duas estações climáticas, sempre maior nas raças taurinas. Contudo, a diferença não ocorreu entre as estações $(\mathrm{P}>0,05)$.

Observou-se efeito negativo da estação chuvosa, a mais quente, $(\mathrm{P}<0,05)$ sobre a motilidade espermática, semelhante ao verificado por Tegegne et al. (1994) e Sudararaman et al. (2000); a motilidade foi maior nos touros de raças taurinas $(\mathrm{P}<0,05)$ em ambas as estações climáticas.

Houve influência da estação climática sobre o vigor dos espermatozóides apenas nas raças zebuínas, maior $(\mathrm{P}<0,05)$ na estação seca, resultado também verificado por Tegegne et al. (1994).

Para verificação da representatividade das categorias de destinação dos ejaculados durante $o$ período estudado, foram excluídos 1.265 obtidos apenas para fins de exames da qualidade inicial do sêmen (categoria 1 dos ejaculados descartados) e 634 ejaculados de touros que já tinham doses suficientes de sêmen em estoque para comercialização (categoria 5 dos ejaculados descartados). Assim, na Tab. 1, com a eliminação das informações das categorias 1 e 5, foram consideradas somente as freqüências observadas nas categorias selecionadas para o estudo. Esses dados forneceram os subsídios para os resultados estatísticos apresentados a seguir, e representam análises distintas das realizadas até o momento.

$\mathrm{Na}$ Tab. 4 apresenta-se o percentual de descartes dos ejaculados por características físicas insuficientes de touros zebuínos e taurinos nas duas estações climáticas. Houve mais descarte de sêmen quanto às características físicas na estação chuvosa do que na seca, mas não houve diferença entre as subespécies, dentro de cada estação. 
Tabela 4. Percentual de ejaculados frescos de touros zebuínos e taurinos descartados por características físicas insuficientes* do sêmen, nas duas estações climáticas

\begin{tabular}{lcc} 
& \multicolumn{2}{c}{ Estação } \\
\cline { 2 - 3 } Subespécie & Chuvosa & Seca \\
\hline Zebuína & $29,0 \mathrm{Aa}$ & $23,0 \mathrm{Ba}$ \\
Taurina & $27,3 \mathrm{Aa}$ & $23,0 \mathrm{Ba}$
\end{tabular}

*Corresponde à categoria 2 da Tab. 1 .

Nas linhas, letras maiúsculas distintas indicam valores diferentes $(\mathrm{P}<0,05)$.

Nas colunas, letras minúsculas iguais indicam valores semelhantes $(\mathrm{P}>0,05)$.

$\mathrm{Na}$ Tab. 5 encontra-se o percentual de descarte dos ejaculados em razão de características morfológicas anormais, acima dos padrões recomendados, dos espermatozóides de touros zebuínos e taurinos, nas duas estações climáticas. Houve mais descarte de sêmen das raças taurinas $(\mathrm{P}<0,05)$ em ambas as estações, sugerindo maior sensibilidade da espermatocitogênese aos fatores climáticos. Todavia, não houve diferença $(\mathrm{P}>0,05)$ entre as estações dentro das subespécies. Na literatura, são encontrados relatos de que touros de raças zebuínas apresentam mais anormalidades espermáticas no período chuvoso (Tegegne et al., 1994) ou menos anormalidades nas duas subespécies em igual período (Kumi-Diaka et al., 1981 e Rekwot et al., 1987). Também são descritas mais anormalidades espermáticas nos touros zebuínos em períodos de temperaturas mais elevadas (Kodagali, 1962, 1963; Tomar e Kanaujia, 1970) e também nas duas subespécies (Koivisto et al., 1998), resultados diferentes dos encontrados neste estudo.

Tabela 5. Percentual de ejaculados frescos de touros zebuínos e taurinos descartados por características morfológicas anormais dos espermatozóides*, nas duas estações climáticas

\begin{tabular}{lcc}
\hline & \multicolumn{2}{c}{ Estação } \\
\cline { 2 - 3 } Subespécie & Chuvosa & Seca \\
\hline Zebuína & $4,3 \mathrm{Ab}$ & $4,0 \mathrm{Ab}$ \\
Taurina & $5,3 \mathrm{Aa}$ & $5,0 \mathrm{Aa}$ \\
\hline *Corresponde à categoria 3 da Tab. 1. \\
Nas linhas, letras maiúsculas iguais indicam valores \\
semelhantes $(\mathrm{P}>0,05)$. \\
Nas colunas, letras minúsculas distintas indicam valores \\
diferentes $(\mathrm{P}<0,05)$.
\end{tabular}

$\mathrm{Na}$ Tab. 6 é apresentado o percentual de descartes de ejaculados por características físicas insuficientes e por características morfológicas anormais dos espermatozóides, acima dos padrões estabelecidos. O descarte de sêmen de touros de raças zebuínas por características físicas e morfológicas, fora dos padrões estabelecidos, foi maior na estação chuvosa $(\mathrm{P}<0,05)$ e nos de raças taurinas o foi na estação seca. Apesar das diferenças entre as estações, os touros zebuínos totalizaram mais descartes do que os das raças taurinas.

Tabela 6. Percentual de ejaculados frescos de touros zebuínos e taurinos descartados por características físicas e morfológicas fora dos padrões estabelecidos*, nas duas estações climáticas

\begin{tabular}{lcc}
\hline & \multicolumn{3}{|c}{ Estação } \\
\cline { 2 - 3 } Subespécie & Chuvosa & Seca \\
\hline Zebuína & $7,4 \mathrm{Aa}$ & $6,3 \mathrm{Bb}$ \\
Taurina & $5,4 \mathrm{Bb}$ & $7,5 \mathrm{Aa}$ \\
\hline
\end{tabular}

*Corresponde à categoria 4 da Tab. 1 .

Nas linhas, letras maiúsculas distintas indicam valores diferentes $(\mathrm{P}<0,05)$.

Nas colunas, letras minúsculas distintas indicam valores diferentes $(\mathrm{P}<0,05)$.

$\mathrm{Na}$ Tab. 7 apresenta-se o percentual de descarte de ejaculados por recuperação insuficiente das características físicas pós-congelação de zebuínos e taurinos nas duas estações climáticas. Observou-se mais descarte nas raças zebuínas $(\mathrm{P}<0,05)$, em ambas as estações climáticas, do que nas raças taurinas. Também houve diferença no descarte $(\mathrm{P}<0,05)$ entre as estações dentro das subespécies. Isto, provavelmente, indica menor resistência na estrutura da membrana espermática do sêmen de zebu para os rigores do processo de congelação, em especial no período em que há maior umidade relativa do ar (estação chuvosa).

Tabela 7. Percentual de ejaculados de touros das raças zebuínas e taurinas descartados por recuperação física pós-congelação insuficiente*, nas duas estações climáticas

\begin{tabular}{lcc} 
& \multicolumn{3}{c}{ Estação } \\
\cline { 2 - 3 } Subespécie & Chuvosa & Seca \\
\hline Zebuína & $17,3 \mathrm{Aa}$ & $15,7 \mathrm{Ba}$ \\
Taurina & $14,0 \mathrm{Ab}$ & $11,5 \mathrm{Bb}$ \\
\hline *Corresponde à categoria $6 \mathrm{da} \mathrm{Tab} .1$. & \\
Nas linhas, letras maiúsculas distintas & indicam valores \\
diferentes $(\mathrm{P}<0,05)$. & & \\
Nas colunas, letras minúsculas distintas & indicam valores \\
diferentes $(\mathrm{P}<0,05)$.
\end{tabular}


$\mathrm{Na}$ Tab. 8 é apresentado o percentual de ejaculados efetivamente congelados, para comercialização, nas subespécies e estações climáticas estudadas. Tanto os touros de raças zebuínas quanto os de raças taurinas tiveram mais ejaculados congelados na estação seca do que na estação chuvosa. Rekwot et al. (1987) e, parcialmente, Djimde e Weninger (1984) verificaram resultados diferentes em relação aos touros das raças zebuínas.

Tabela 8. Percentual de ejaculados congelados de touros zebuínos e taurinos*, nas duas estações climáticas

\begin{tabular}{lcc}
\hline & \multicolumn{3}{c}{ Estação } \\
\cline { 2 - 3 } Subespécie & Chuvosa & Seca \\
\hline Zebuína & $42,0 \mathrm{Bb}$ & $51,0 \mathrm{Aa}$ \\
Taurina & $48,0 \mathrm{Ba}$ & $53,0 \mathrm{Aa}$ \\
\hline
\end{tabular}

*Corresponde à categoria $7 \mathrm{da}$ Tab. 1

Nas linhas, letras maiúsculas distintas indicam valores diferentes $(\mathrm{P}<0,05)$.

Nas colunas, letras minúsculas distintas indicam valores diferentes $(\mathrm{P}<0,05)$.

Do total dos ejaculados $(n=12.140)$ considerados aptos para serem congelados, correspondentes às categoria 6 e 7 da Tab. 1, o percentual daqueles que apresentaram congelabilidade, nas respectivas estações, é apresentado na Tab. 9.

Tabela 9. Percentual de ejaculados de touros zebuínos e taurinos que apresentaram congelabilidade, nas duas estações climáticas

\begin{tabular}{lcc}
\hline & \multicolumn{2}{c}{ Estação } \\
\cline { 2 - 3 } Subespécie & Chuvosa & Seca \\
\hline Zebuínas & $71,0 \mathrm{Bb}$ & $76,0 \mathrm{Ab}$ \\
Taurinas & $77,0 \mathrm{Ba}$ & $82,0 \mathrm{Aa}$ \\
\hline
\end{tabular}

*Corresponde às categorias 6 e 7 da Tab. 1 .

Nas linhas, letras maiúsculas distintas indicam valores diferentes $(\mathrm{P}<0,05)$.

Nas colunas, letras minúsculas distintas indicam valores diferentes $(\mathrm{P}<0,05)$.

Alguns ejaculados foram descartados por não resistirem ao processo de congelação (categoria 6). Aqueles que superaram essa fase (categoria 7) por apresentarem, após a congelação, motilidade espermática acima de $35 \%$ e vigor dos espermatozóides acima de 4,0 foram os utilizados no estudo da congelabilidade. A motilidade dos espermatozóides do sêmen de zebuínos e taurinos, na pré-congelação foi semelhante e melhor na estação seca, $67,8 \pm 6,3 \%$ e $67,8 \pm 6,4 \%$, do que na estação chuvosa,
$67,6 \pm 6,5 \%$ e $67,5 \pm 6,5 \%$, respectivamente. Entretanto, o sêmen de touros de raças taurinas apresentou melhor recuperação da motilidade $(\mathrm{P}<0,05)$ do que o sêmen de touros zebuínos,

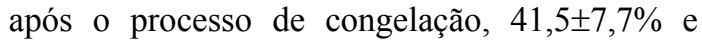
$38,0 \pm 8,2 \%$, respectivamente. O vigor do sêmen dos zebuínos na pré-congelação, embora, tenha sido menor $(4,8 \pm 0,1)$ na estação chuvosa $(\mathrm{P}<0,05)$ em relação ao da estação seca, e menor em relação ao dos taurinos nas duas estações $(4,9 \pm 0,1)$, na pós-congelação não se verificou qualquer efeito de estação climática sobre $o$ vigor $(4,9 \pm 0,2)$.

A Tab. 10 apresenta o número e o percentual dos ejaculados congelados nas duas subespécies e nas duas estações climáticas.

Tabela 10. Ejaculados congelados de touros zebuínos e taurinos, nas duas estações climáticas

\begin{tabular}{lcccc} 
& \multicolumn{4}{c}{ Estação } \\
\cline { 2 - 5 } Subespécie & \multicolumn{2}{c}{ Chuvosa } & \multicolumn{2}{c}{ Seca } \\
\cline { 2 - 5 } Z & \% & n & $\%$ \\
\hline Zebuína & 2552 & 43,0 & 3376 & 57,0 \\
Taurina & 1589 & 48,5 & 1687 & 51,5 \\
Total & 4141 & 45,0 & 5063 & 56,0 \\
\hline
\end{tabular}

O processo seletivo do sêmen, feito na précongelação, mostra que houve coerência, visto que todos os ejaculados das duas subespécies e nas duas estações climáticas resultaram em motilidade espermática média de $67,5 \%$ e vigor médio dos espermatozóides de 4,9. Após a congelação, o vigor dos espermatozóides permaneceu o mesmo e a motilidade espermática média mostrou-se superior na estação seca $(\mathrm{P}<0,05)$ nas duas subespécies. A motilidade dos espermatozóides dos taurinos foi superior $(41,5 \%$ e $40,6 \%)$ à dos zebuínos $(38,0 \%$ e $36,7 \%)$, sugerindo melhor congelabilidade, em ambas as estações climáticas.

\section{CONCLUSÕES}

A estação pode interferir na qualidade do sêmen de touros doadores em central de inseminação artificial e na sua eficiência para congelação. Nas condições térmicas, pluviométricas e de umidade relativa do ar do Sudeste brasileiro, os taurinos apresentam mais eficiência no processo de congelação de sêmen do que os zebuínos. Também apresentam, na pré-congelação, 
melhores indicadores de avaliação do sêmen, sugerindo pouca susceptibilidade a efeitos climáticos mais severos do que os observados em climas temperados.

\section{REFERÊNCIAS BIBLIOGRÁFICAS}

DJIMDE, M.; WENIGER, J.H. Semen quality of bulls in relation to breeding groups and seasons in Bangladesh. Zeitisch. Tierzuch. Zuchtungsbiol., v.101, p.59-69, 1984.

FIELDS, M.J.; BURNS, W.C.; WARNICK, A.C. Age, season and breed effects on testicular volume and semen traits in young bulls. J. Anim. Sci., v.48, p.1299-1304, 1979.

FONSECA, V.O.; VALE FILHO, V.R.; MIES FILHO, A. et al. Procedimentos para exame andrológico e avaliação de sêmen animal. Belo Horizonte: CBRA, 1992. 79p.

HERNANDEZ, E.; GALINA, C.S.; ORIHUELA, A. et al. Observations on freezing capability and seminal characteristics in four breeds of Bos indicus cattle. Anim. Reprod. Sci., v.25, p.23-29, 1991.

KODAGALI, S.B. Observations on the semen characteristics and reaction time of Khillar breed of cattle. Indian J. Vet. Sci., v.33,p.26-28, 1963.

KODAGALI, S.B. Seasonal variation in semen characteristics and reaction time of Khillar breed. Indian Vet. J., v.39, p.593-599, 1962.

KOIVISTO, M.B.; NOGUEIRA, G.P.; COSTA, M.T.A. Seasonal variations of morphological abnormalities in bovine spermatozoa. In: SIPAR, 4; SEMINAR ON ANIMAL REPRODUCTION AND BIOTECHNOLOGY FOR LATIN AMERICA, 1998, Belém, PA. Proceedings... Uppsala: Swedish University of Agricultural Sciences, 1998. v.2, p.5056.

KUMI-DIAKA, J.; NAGARATNAM, V.; RWUAAN, J.S. Seasonal and age-related changes in semen quality and testicular morphology of bulls in a tropical environment. Vet. Rec., v.108, p.13-15, 1981.

MATHEVON, M.; BUHR, M.M.; DEKKERS, J.C.M. Environmental, management, and genetic factors affecting semen production in Holstein bulls. J. Dairy Sci., v.81, p.3321-3330, 1998.

MENENDEZ-BUXADERA，A.; MORALES，J.R.; PEREZ, A.P. et al. Seasonal variation in semen production of Holstein, zebu and criollo bulls under artificial insemination conditions in Cuba. In: REPRODUCTION DES RUMINANTS EN ZONE TROPICALE, REUNION INTERNATIONALE, 1983, Pointe-a-Pitre. Les colloques de L'INRA. Paris: INRA, 1984. n.20, p.239-249.
PINTO, P.A. Análise da morfologia testicular e da produção e características de sêmen de reprodutores zebus da raça Nelore. 1987. 87f. Dissertação (Mestre em Ciências) - Faculdade de Medicina de Ribeirão Preto, Universidade de São Paulo, Ribeirão Preto, SP.

REKWOT, P.I.; VOH Jr., A.A.; OYEPIDE, O.E. et al. Influence of season on characteristics of the ejaculate from bulls in artificial centre in Nigeria. Anim. Reprod. Sci., v.14, p.187-194, 1987.

SILVA, J.L. Causas da variação na quantidade $e$ qualidade do sêmen de touros em colheita em Centrais de Inseminação Artificial. 1981 75f. Tese (Mestre em Zootecnia) - Escola de Veterinária, Universidade Federal de Minas Gerais, Belo Horizonte, MG.

SNEDECOR, G.W.; COCHARAN, W.G. Statistical methods. 8.ed. Ames: Iowa State University, 1989. $503 \mathrm{p}$.

SÖDERQUIST, L.; JANSON, L.; HAARD, M. et al. Influence of season, age, breed and some other factors on the variation in sperm morphological abnormalities in Swedish dairy A.I. bulls. Anim. Reprod. Sci., v.44, p.91-98, 1996.

STATISTICAL package for social science (SPSS) for windows 8.0.0. Chicago: 1997. ICD-ROM.

SUNDARARAMAN, M.N.; THANGARAJU, P.; EDWIN, M.J. Non-genetic sources of variation influencing semen production in Jersey bulls. Indian J. Anim. Sci., v.70, p.652-653, 2000.

TEGEGNE, A.; DEMBARGA, Y.; KASSA, T. et al. Effect of plane of nutrition and season on body and testicular growth and on semen characteristics in Boran and Boran $\times$ Friesian bulls in Ethiopia. Anim. Reprod. Sci., v.36, p.197-209, 1994

TOMAR, S.S.; KANAUJIA, A.S. Seasonal variation in reaction time and semen characteristics of Hariana bulls. J. Res. Punjab Agric. Univ., v.7, p.541-545, 1970.

VALE FILHO, V.R. Andrologia no touro: avaliação genital, exame do sêmen e classificação por pontos. Rev. Bras. Reprod. Anim., v.21, p.7-13, 1997.

VALE FILHO, V.R. Padrões de sêmen bovino, para o Brasil: análise e sugestões. In: CONGRESSO BRASILEIRO DE REPRODUÇÃO ANIMAL, 8., Belo Horizonte. Palestras ... Belo Horizonte: CBRA, 1989. p.94-118.

VALE FILHO, V.R. Subfertilidade em touros: parâmetros para avaliação andrológica e conceituação geral. Cad. Téc. Vet. Zootec., n.35, p.81-87, 2001.

VALE FILHO, V.R.; PINHEIRO, L.E.L.; BASRUR, P.K. Reproduction in zebu cattle. In: MORROW, D.A. (Ed.) Current therapy in theriogenology. 2.ed. Philadelphia: W.B. Saunders, 1986. p.437-442. 